\title{
Pre-operative mean corpuscular volume, red cell distribution width and neutrophil-to-lymphocyte ratio in patients with enchondroma
}

\author{
Sezai Özkan*, Cihan Adanaş, Ferhat Danışman \\ Department of Orthopaedics and Traumatology, Van Yuzuncu Yil University Dursun Odabas Medical Center, Van, \\ Turkey
}

\begin{abstract}
Enchondromas are benign, solitary bone tumors originating from hyaline cartilage, that are usually located in the upper and lower extremities. They are equally distributed in both genders and in all age groups. $40-65 \%$ of enchondromal cases are found in metacarpal bones. The most common involvement is the proximal phalanx, metacarpal bone, and distal phalanx. Involvement of distal phalanx in patients with enchondroma is rare. Our aim in this study was to investigate the preoperative neutrophil count, white blood cell count, red cell distribution width, mean corpuscular volume, platelet count, hemoglobin, hematocrit and NLR values, and make a comparison with a control group. The most commonly involved sites are also investigated in the patient group.

This retrospective study investigated the preoperative WBC, neutrophil, lymphocyte, RDW, MCV, NLR values in 20 patients and 20 controls, and compared the frequency of the involved sites among patients with enchondroma.

WBC, neutrophil count, MCV, RDW were not found statistically significant. NLR ratios were different between groups, but not statistically significant. Involvement of the proximal phalanx was statistically significantly higher $(\mathrm{p}<0.05)$.

This is the first study investigating the pre-operative RDW, MCV, NLR, PLT, Hgb, Hct and WBC in patients with enchondroma. Although there is no statistically significant difference when these results are compared we suggest that they should be studied in larger groups and in clinical tests, so that the malignancy potential may be predicted.
\end{abstract}

Key Words: Enchondroma, neutrophil-to-lymphocyte ratio, mean corpuscular volume, leukocyte count red cell distribution width

\section{Introduction}

Enchondromas are benign bone tumors originating from hyaline cartilage. These intramedullar cartilage lesions are believed to be hamartomatous remnants of the growing plate $(1,2)$. They are solitary lesions located usually in the upper and lower extremities (3,4). While 40$70 \%$ of patients with enchondroma are localized in the hands and small bones in the legs, $25 \%$ of the cases are seen in long tubular bones $(5,6)$.

Diagnosis is usually made based on the presence of a painful or painless swelling, a pathological fracture or an incidental radiological finding (7-9). These lesions are usually followed-up with conservative methods. When surgery is indicated, curettage and filling the space with bone graft or supportive materials are performed (5).

This retrospective study compared the preoperative blood values hematocrit (Hct), hemoglobin (Hgb), white blood cell (WBC), platelet (PLT), red cell distribution width (RDW), mean corpuscular volume (MCV), and the neutrophil/lymphocyte ratio (NLR)] between patients with enchondroma and the control group, and also investigated the location of the tumor in the patient group. Patients who had an inflammatory disease, diabetes, steroid use, alcohol use or who smoked were excluded from the study group.

\section{Material and methods}

Study Plan: The patients who had been diagnosed with enchondroma at the Orthopedics and Traumatology Clinic of Medical School, Van Yuzuncu Yil University between 2010-2017, were retrospectively evaluated with regard to age, gender, tumor location, pre-operative Hgb, Hct, RDW, MCV, WBC, neutrophil count and the NLR values and compared with control group. The data were collected from the patient files.

Each group was composed of 20 patients. Data regarding the involvement site and the pre- 
operative blood values were obtained from the patient files. The main reasons for admission were determined as pain, restricted movement and swelling of the finger. Patients with diabetes mellitus, hypertension, infectious diseases, pulmonary diseases, those who smoked, those who used steroids and alcohol were excluded from the study. Twenty healthy individuals with no known systemic diseases, who did not smoke or drink alcohol were selected as controls.

MCV, RDW and NLR: The blood count was assessed by means of a Beckman-Coulter, LH 780, USA instrument. White blood cell, neutrophil, lymphocyte and platelet counts, RDW and MCV values were taken from this device. The MCV values were measured from the blood parameters collected in the EDTA tube while the NLR values were calculated by obtaining the neutrophil / lymphocyte ratio of the values from the blood samples.

\section{Results}

The mean age was $24.7 \pm 11.26$ years for the patient group and $24 \pm 16.38$ years for the control group. There was similarity between groups according to age and sex $(\mathrm{p}>0.05)$ (Table 1). Although the number of neutrophils, lymphocytes, NLR, RDW and PLT were higher in the patient group, no statistically significant difference was found $(p>0.05)$ (Table 1$)$.

Table 1. Demographic and clinical parameters of the patients with enchondroma and healthy subjects (values are expressed as mean \pm standard deviation)

\begin{tabular}{llll}
\hline Parameters & Study group $(\mathrm{n}=20)$ & Control group $(\mathrm{n}=20)$ & $\mathrm{p}$ value \\
\hline Age (years) & $24.7 \pm 11.26$ & $24 \pm 16.38$ & 0.87 \\
Gender (female/male) & $9 / 11$ & $10 / 10$ & 0.75 \\
PLT count $(\mathrm{x} 103 / \mathrm{mm} 3)$ & $255.83 \pm 78.70$ & $303.90 \pm 174.48$ & 0.29 \\
MCV (fl) & $83.36 \pm 5.68$ & $84.31 \pm 7.07$ & 0.65 \\
ANC (cell/mm3) & $5.64 \pm 1.95$ & $7.36 \pm 4.43$ & 0.13 \\
ALC (cell/mm3) & $2.26 \pm 0.87$ & $2.33 \pm 1.06$ & 0.84 \\
RDW $(\%)$ & $13.63 \pm 1.26$ & $14.29 \pm 1.45$ & 0.14 \\
NLR $(\%)$ & $2.72 \pm 1.11$ & $3.61 \pm 2.65$ & 0.18 \\
WBC $(/ \mu \mathrm{l})$ & $8.74 \pm 2.19$ & $9.73 \pm 4.90$ & 0.43 \\
Hgb & $13.75 \pm 1.99$ & $12,82 \pm 2.30$ & 0.19 \\
Hct & $40.92 \pm 5.92$ & $39.45 \pm 7.73$ & 0.51 \\
\hline
\end{tabular}

Abbreviations: PLT: platelet, MCV: mean corpuscular volume, ANC: absolute neutrophil count, ALC: absolute lymphocyte count, RDW: red cell distribution width; NLR: neutrophil to lymphocyte ratio; WBC: white blood cell, Hgb: hemoglobin, Hct: hematoctrit

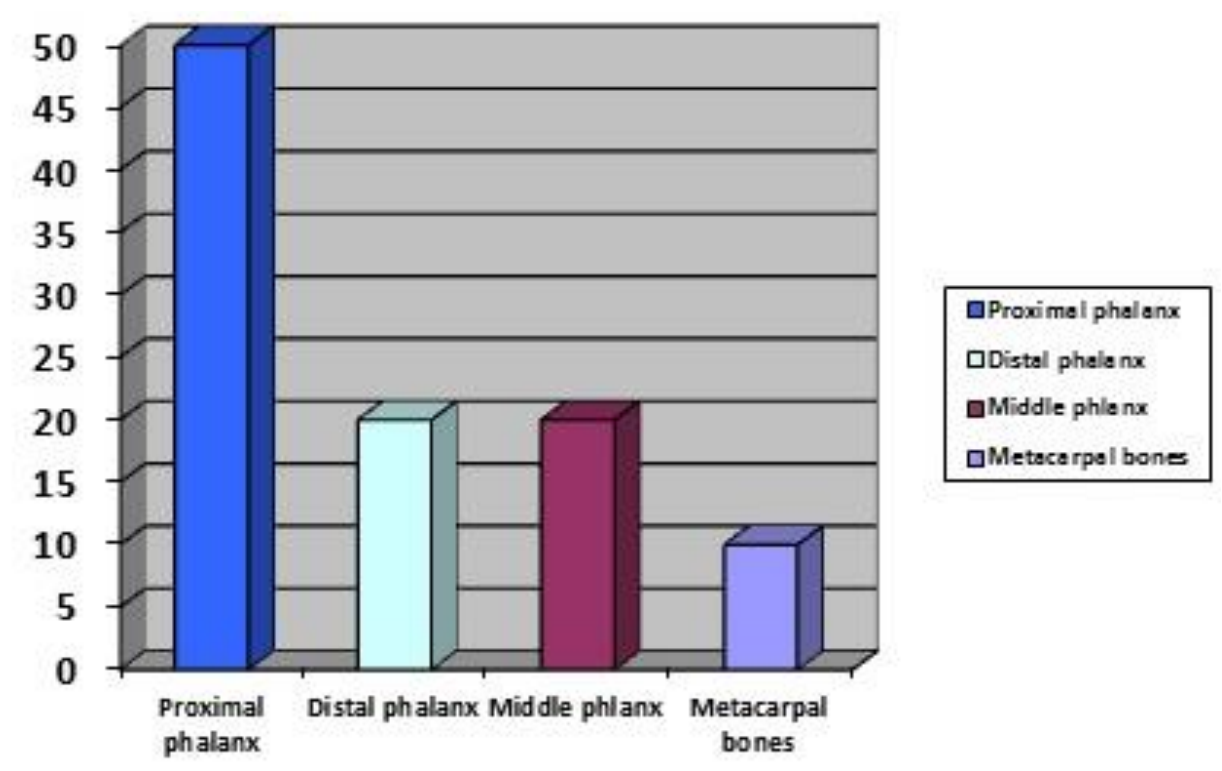

Fig. 1. Distribution of involvement in the hand. 
The proximal phalanx was determined to be the most commonly involved site (Figure 1).

Statistical analysis: Independent sample t-test was used to compare the parameters of the blood tests and the age and sex of the patients. Chisquare test was used for the localization of the enchondroma in the hand bones. Student's t tests were used to compare the parameters. The results were evaluated as mean \pm standard deviation. The results were accepted as significant when $\mathrm{p}$ values less than 0.05. Statistical Package Program for Social Sciences (SSPS) was used for statistical analysis.

\section{Discussion}

When we checked the literature, we thought that these blood values are the first to study preoperatively in patients with enchondroma. Although this parameter in the complete blood count was higher in the patient group, it did not seem to be statistically significant.

Enchondroma is a benign tumor of the hyaline cartilage. The lesions are commonly located within the bone. While the vast majority of the tumors are solitary, more than one bone or more than one location in one bone may rarely be involved (10). Enchondromas are distributed almost equally in both gender and in each age group (4). 40-65\% of the cases are seen in the small tubular bones of the hands, most frequently in the proximal phalanx, metacarpal bones, middle phalanx and rarely in distal phalanx (11). They are seen in the middle and distal parts of the metacarpal bones and more in proximal part of phalanges. The tubular bones of the feet are involved seven-fold less frequently than the hand. Enchondromas are almost never seen in the carpal or the tarsal bones. While most of the enchondromas may be seen in the femur, humerus, tibia, radius, ulna and fibula are rarely involved, and flat bones are involved very rarely too (12).

Our study has revealed that involvement of the proximal phalanx is statistically significantly higher than the middle phalanx, distal phalanx and metacarpal bone $(\mathrm{p}<0.05)$ (Table 2$)$.

When the patients were investigated with regard to the involvement site in the hand, proximal phalanx involvement was determined to be statistically significantly higher than involvement of the middle phalanx, distal phalanx and the metacarpal bones $(\mathrm{p}<0.05)$ (Figure 1$)$.

A potential relationship between systemic inflammation and malignancy development has gained great importance in recent studies (13).
Table 2. Comparison of the patients with regard to lesion localization in the hand

\begin{tabular}{|c|c|c|c|}
\hline Localization & Frequency & $\begin{array}{c}\text { Percent } \\
(\%)\end{array}$ & $\begin{array}{l}\mathrm{p} \\
\text { value }\end{array}$ \\
\hline Proximal phalanx/ & 10 & 50.0 & \multirow{2}{*}{0.036} \\
\hline Distal phalanx & 4 & 20.0 & \\
\hline Proximal phalanx/ & 10 & 50.0 & \multirow{2}{*}{0.036} \\
\hline Middle phalanx & 4 & 20.0 & \\
\hline Proximal & 10 & 50 & \multirow[b]{2}{*}{0.002} \\
\hline $\begin{array}{l}\text { phalanx/Metacarpal } \\
\text { bones }\end{array}$ & 2 & 10 & \\
\hline
\end{tabular}

Although the exact mechanism is not known, some hypotheses have been proposed. Tumorrelated inflammation may lead to increased level of cytokines, inhibition of apoptosis and increased angiogenesis. Tumor cells increase the granulocyte colony-stimulating factor (G-CSF) release, which triggers the increase in neutrophil count. Neutrophils play a role in tumor angiogenesis through producing pro-angiogenetic factors such as vascular endothelial growth factor, matrix metalloproteinase, interleukin-8 and elastases (1418). While these cytokine species contribute to tumor growth and metastases, lymphocytes have a significant role in tumor suppression (19). Increased lymphocyte count is known as a positive factor in colorectal cancer, breast cancer and melanoma (20-22). Both increased neutrophil count and decreased lymphocyte count may lead to increased NLR, which has been reported to a prognostic factor in many cancer types. Leukocyte migration is important in the physiological immune response and accompanies systemic changes triggered by circulating cytokines and chemokines. These changes may lead to increased neutrophil and platelet count and decreased lymphocyte count. These changes have been proposed to have an important role in growth, progression and metastasis of the neoplasm (23). Neutrophilia may develop as a result of infection accompanied by para-neoplastic myeloid growth factors or cancer-related inflammation (24). Lymphocytes have an important role in defense against tumor through induction of cell death via the immune response. Lymphopenia is frequently seen in developed cancers and this is an indicator of a suppressed immune response due to cancer (25). Therefore, neutrophilia and lymphopenia may be erroneous due to cancer progression. Elevated NLR may result from the systemic inflammatory response due to cancer, which could lead to neutrophilia and lymphocytopenia (26). High WBC may be directly related to 
inflammation, especially in cardiovascular diseases (27).

NLR is nowadays defined as a marker of inflammation and is used as an index in cancer diagnosis and treatment $(28,29)$. Elevated NLR is a prognostic factor in many cancer types $(30,31)$. Kum et al. have shown that NLR was significantly elevated in laryngeal cancer when they compared benign and malignant lesions (32). Although high NLR values are defined as poor prognosis in some types of cancer, some conflicting studies also exist (33-35). Preoperative elevated NLR may be correlated with poor survival expectation, advanced stage cancer, poor prognosis and inflammation (36). Several studies have reported that NLR is an significant predictor for coronary artery disease, acute coronary syndrome, heart failure and diabetic nephropathy (37). A metaanalysis by Paramanathan et al. has indicated that elevated NLR is associated with a poor prognosis in patients with solid tumors (14). Wang et al. have determined that increased NLR $(>3)$ is related a poor prognosis in patients who have bone metastases (38).

Our study has not revealed a significant difference between the patient and the control groups with regard to NLR. This result may be associated with the small number of patients. Furthermore, enchondroma may not have affected the inflammatory parameters due to being a chronic disease, which progresses slowly. NLR has been used as a prognostic factor in recent studies. We suggest that NLR may be used as an inexpensive, non-invasive method for malignant transformation of enchondroma due to the potential for malignant transformation, although very rare. The NLR value may be useful for clinicians for this rare and insidious condition. Further studies with larger series are required for better understanding this issue.

Conflict of interest statement: The authors declare no conflict of interest in this article

Financial disclosure: The authors have not received any financial support for this study

\section{References}

1. Cabay RJ, Reddy V, David O et al: Cytologic features of primary chondroid tumors of bone in crush preparations.Diagn Cytopathol 2008; 36: 758-761.

2. Walden MJ, Murphey MD, Vidal JA. Incidental enchondromas of the knee. AJR Am J Roentgenol 2008; 190: 1611-1615.
3. Van der Geest IC, de Valk MH, de Rooy JW, et al: Oncological and functional results of cryosurgical therapy of enchondromas and chondrosarcomas grade 1. J Surg Oncol 2008; 98: 421-426.

4. Ojeda Thies C, Bonsfills N, Albinana J. Solitary epiphyseal enchondroma of the proximal femur in a 23 month old girl. J Pediatr Orthop 2008; 28: 565-568.

5. Adaş M, Yurdoğlu HC, Tombul M, et al: Femur alt uç enkondromlarının küretaj ve kemik çimentosu ile tedavi sonuçları. Acta Orthop Traumatol Turc 2007; 41: 380386.

6. Kaya T. Kas iskelet - yumuşak doku radyolojisi. 1.bask1. Bursa: Nobel \& Güneş Tıp Kitabevi; 2008.s.509.

7. Malizos KN, Gelalis ID, Ioachim EE, et al: Pathologic fracture of the scaphoid due to enchondroma:treatment with vascularized bone grafting. Report of a case.J Hand Surg [Am] 1998; 23: 334-337.

8. Canovas F, Nicolau F, Bonnel F. Avulsion of the flexor digitorum profundus tendon associated with a chondroma of the distal phalanx. J Hand Surg 1998; 23: 130-131.

9. Shimizu K, Kotoura Y, Nishijima N, et al: Enchondroma of the distal phalanx of the hand. J Bone Joint Surg 1997; 79: 898-900.

10. Lucas DR, Bridge JA. Chondromas: enchondroma, periosteal chondroma, and enchondromatosis. In: Fletcher CDM, Unni KK, Mertens F, editors. World Health Organization Classification of Tumours. Pathology and Genetics of Tumours of Soft Tissue and Bone. Lyon: IARC Press; 2002. P.237-240.

11. Resnick D, Kyriakos M, Greenway GD. Tumors and tumor-like lesions of bone: Imaging and pathology of specific lesions. In: Resnick D, editor. Diagnosis of Bone and Joint Disorders, 3rd ed. Philadelphia: WB Saunders; 1995. P.36293647.

12. Murphey MD, Flemming DJ, Boyea SR, et al. Enchondroma versus chondrosarcoma in the appendicular skeleton: differentiating situations. Radiographics 1998; 18: 1213-1237.

13. Hanahan D, Weinberg RA. Hallmarks of cancer: the next generation. Cell 2011; 144: 646-674.

14. Paramanathan A, Saxena A, Morris DL. A systematic review and meta-analysis on the impact of pre-operative neutrophil lymphocyte ratio on long term outcomes after curative intent resection of solid tumours. Surg Oncol 2014; 23: 31-39.

15. Coussens LM, Werb Z. Inflammation and cancer. Nature 2002; 420: 860-867.

16. Balkwill F, Mantovani A. Inflammation and cancer: Back to Virchow? Lancet 2001; 357: 539545. 
17. Mantovani A, Allavena P, Sica A, et al: Cancerrelated inflammation. Nature 2008; 454: 436-444.

18. Kusumanto YH, Dam WA, Hospers GA, et al: Platelets and granulocytes, in particular the neutrophils, form important compartments for circulating vascular endothelial growth factor. Angiogenesis 2003; 6: 283-287.

19. Kitayama J, Yasuda K, Kawai K, Sunami E, Nagawa H. Circulating lymphocyte is an important determinant of the effectiveness of preoperative radiotheraphy in advanced rectal cancer. BMC Cancer 2011; 11: 64.

20. Ogino S, Nosho K, Irahara N, et al: Lymphocytic reaction to colorectal cancer is associated with longer survival, independent of lymph node count, microsatellite instability, and cpg island methylator phenotype. Clin Cancer Res 2009; 15: 6412-6420.

21. Mahmoud SM, Paish EC, Powe Dg et al: Tumorinfiltrating CD8+lymphocytes predict clinical outcome in breast cancer. J Clin Oncol 2011; 29: 1949-1955.

22. Clemente CG, Mihm MC Jr, Bufalino R, Zurrida S, Collini P, Cascinelli N. Prognostic value of tumor infiltrating lymphocytes in the vertical growth phase of primary cutaneous melanoma. Cancer 1996; 77: 1303-1310.

23. Ertas IE, Gungorduk K, Akman L, et al: Can preoperative neutrophil: lymphocyte and platelet: lymphocyte ratios be used as predictive markers for lymph node metastasis in squamous cell carcinoma of the vulva? Eur J Obstet Gynecol Reprod Biol 2013; 171: 138-142.

24. Teramukai S, Kitano T, Kishida Y, et al: Pretreatment neutrophil count as an independent prognostic factor in advanced non-small-cell lung cancer: an analysis of Japan Multinational Trial Organisation LC00-03. Eur J Cancer 2009; 45: 1950-1958.

25. Maltoni M, Pirovano M, Nanni O, et al : Biological indices predictive of survival in 519 Italian terminally ill cancer patients. Italian Multicenter Study Group on Palliative Care. J Pain Symptom Manage 1997; 13: 1-9.

26. Mallappa S, Sinha A, Gupta S, et al: Preoperative neutrophil to lymphocyte ratio $>5$ is a prognostic factor for recurrent colorectal cancer. Colorectal Dis 2013; 15: 323-328.

27. Horne BD, Anderson JL, John JM, et al: Intermountain Heart Collaborative Study Group. Which white blood cell subtypes predict increased cardiovascular risk? J Am Coll Cardiol 2005; 10: 1638-1643.

28. Zahorec R. Ratio of neutrophil to lymphocyte counts - rapid and simple parameter of systemic inflammation and stress in critically ill. Bratisl Lek Listy 2001; 102: 5-14.

29. Kacan T, Babacan NA, Seker M, et al: Could the neutrophil to lymphocyte ratio be a poor prognostic factor for non small cell lung cancers? Asian Pac J Cancer Prev 2014; 15: 2089-2094.

30. Li J, Jiang R, Liu WS, et al: A large cohort study reveals the association of elevated peripheral blood lymphocyte-to-monocyte ratio with favorable prognosis in nasopharyngeal carcinoma. Plos One 2013; 8: e83069.

31. Fu SJ, Shen SL, Li SQ, et al: Prognostic value of preoperative peripheral neutrophilto-lymphocyte ratio in patients with $\mathrm{HBV}$-associated hepatocellular carcinoma after radical hepatectomy. Med Oncol 2013; 30: 721.

32. Kum RO, Ozcan M, Baklaci D, et al: Elevated neutrophil-to-lymphocyte ratio in squamous cell carcinoma of larynx compared to benign and precancerous laryngeal lesions. Asian Pac J Cancer Prev 2014; 15: 7351-7355.

33. Goh BK, Chok AY, Allen JC Jr, et al: Blood neutrophil-to-lymphocyte and platelettolymphocyte ratios are independent prognostic factors for surgically resected gastrointestinal stromal tumors. Surgery 2016; 159: 1146-1156.

34. Han S, Liu Y, Li Q, et al: Pre-treatment neutrophil-to-lymphocyte ratio is associated with neutrophil and T-cell infiltration and predicts clinical outcome in patients with glioblastoma. BMC Cancer 2015; 15: 617.

35. Suppan C, Bjelic-Radisic V, La Garde M, et al: Neutrophil/lymphocyte ratio has no predictive or prognostic value in breast cancer patients undergoing preoperative systemic therapy. BMC Cancer 2015; 15: 1027.

36. Chen ZY, Raghav K, Lieu CH, et al: Cytokine profile and prognostic significance of high neutrophil-lymphocyte ratio in colorectal cancer. Br J Cancer 2015; 112: 1088-1097.

37. Huang W, Huang J, Liu Q, et al: Neutrophillymphocyte ratio is a reliable predictive marker for early-stage diabetic nephropathy. Clin Endocrinol (Oxf) 2015; 82: 229-233.

38. Wang S, Zhang Z, Fang F, et al: The neutrophil/lymphocyte ratio is an independent prognostic indicator in patients with bone metastasis. Oncol Lett 2011; 2: 735-740. 